\title{
Antifungal and Cytotoxic Activities of Biosynthesized Silver, Zinc and Gold Nanoparticles by Flower Extract of Rhanterium epapposum
}

\author{
Mohammed S. J. Al Qhtani1, Samah A. El-Debaiky², Mahmoud Sayed ${ }^{3,4}$ \\ ${ }^{1}$ Department of Biology, Faculty of Science, King Khalid University, Abha, Saudi Arabia \\ ${ }^{2}$ Department of Botany and Microbiology, Faculty of Science, Tanta University, Tanta, Egypt \\ ${ }^{3}$ Department of Physics, Faculty of Science, King Khalid University, Abha, Saudi Arabia \\ ${ }^{4}$ Department of Physics, Faculty of Science, Al Azhar University, Assiut, Egypt \\ Email: *samaheldebaiky@science.tanta.edu.eg
}

How to cite this paper: Al Qhtani, M.S.J., El-Debaiky, S.A. and Sayed, M. (2020) Antifungal and Cytotoxic Activities of Biosynthesized Silver, Zinc and Gold Nanoparticles by Flower Extract of Rhanterium epapposum. Open Journal of Applied Sciences, 10, 663-674.

https://doi.org/10.4236/ojapps.2020.1011046

Received: September 30, 2020

Accepted: November 9, 2020

Published: November 12, 2020

Copyright $\odot 2020$ by author(s) and Scientific Research Publishing Inc. This work is licensed under the Creative Commons Attribution International License (CC BY 4.0).

http://creativecommons.org/licenses/by/4.0/

\section{(c) (i) Open Access}

\begin{abstract}
This study was designed to prepare silver, zinc and gold nanoparticles (NPs), AgNPs, ZnNPs and AuNPs, by biosynthesis technique using methanolic extract of Rhanterium epapposum flowers using $\mathrm{AgNO}_{3}, \mathrm{Zn}\left(\mathrm{CH}_{3} \mathrm{CO}_{2}\right)_{2}$ and $\mathrm{HAuCl}_{4} \cdot 3 \mathrm{H}_{2} \mathrm{O}$ as starting materials. The physical properties of the formed NPs were characterized by ultraviolet spectroscopy (UV), X-ray diffraction (XRD), transmission electron microscopy and Fourier transformed infrared spectroscopy (FTIR). The results revealed that, AgNPs were homogeneous and spherical in shape, with average diameter $16.3 \mathrm{~nm}$. While, ZnNPs were approximately triangle and hexagonal shaped, with average diameter 23.5 $\mathrm{nm}$. Most of the synthesized AuNPs were spherical in shape with average diameter $17.9 \mathrm{~nm}$. The antifungal activity of different concentrations of the formed AgNPs, ZnNPs and AuNPs was tested against two human pathogens: Candida albicans and Aspergillus melleus and one plant pathogenic fungus: Phoma exigua, using agar diffusion assay. The best results recorded by 120 $\mu \mathrm{g} / \mathrm{ml}$ AgNPs against the human pathogen: $C$. albicans where the inhibition zone was $23.5 \mathrm{~mm}$. Additionally, the cytotoxicity of the tested NPs was evaluated against Breast adenocarcinoma (MCF-7), Hepatocellular carcinoma (HepG-2) and colorectal carcinoma (HCT 116) human cell lines. The most toxic was AuNPs where the IC50 against MCF-7, HepG2 and HCT116 was $55.02,66.44$ and $169.87 \mu \mathrm{g} / \mathrm{mL}$ respectively.
\end{abstract}

\section{Keywords}

Nanoparticles, Rhanterium epapposum, Biosynthesis, Antifungal, 
Cytotoxicity

\section{Introduction}

Nanoparticles are considered as the building blocks of nanotechnology that they were synthesized in the range of $1-100 \mathrm{~nm}$ [1] [2]. The synthesis of NPs by biological methods is rapidly growing for the field of nanotechnology due to its low toxicity and relatively cheap. Thus, these methods are reported as an economical valuable and alternative source for the synthesis of metal NPs [3]. Among all noble metal NPs, silver, zinc and gold had an interest based on their distinctive properties using different experiments as antibacterial activity [2] [4] [5], antitumor [1] [3], catalytic activity [6] [7] and chemical stability [8] [9] [10].

Incidentally, the researchers concern was attracted by the production possibility of NPs by biological methods. This was performed by using bacteria, algae, fungi or plant extracts as an alternative to the chemical and physical methods for producing NPs [11] [12]. The biosynthesis of NPs, which mediated by microbes, is not industrially feasible, because it requires the preservation of highly aseptic conditions and expensive growth media to grow [13]. It was reported that plant extracts showed numerous advantages, such as availability, safety handling and viability of metabolites. Moreover, the reaction media for the synthesis of inorganic NPs is more interesting over other microorganisms as well as less hazard than other organisms [14].

Medicinal plants possess high safety profile as well as high effectiveness, so, they are useful for human beings in many applicatory uses [15]. They are considered as an important source of bioactive metabolites which can be used for treatment of many diseases. In the meantime, some of these plant metabolites play vital roles as reducing and capping agents in metals NPs biosynthesis [16]. The green method for creating metal NPs is aimed at striving against the safety of applications of the nanotechnology, especially in medical fields.

Recently, there are several publications interested in application of nanotechnology in drug discovery. These reports showed the effect of Musa acuminata [3], Echinochloa frumentacea [5], Clinacanthus nutans [9], that used for biological synthesis of silver, zinc and gold NPs.

As there is no available reviews or publications indicated the production of metals NPs using the flower of Rhanterium epapposum (family: Asteraceae) which is considered a rich source of volatile compounds including limonene, linalool, 4-terpineol and $\alpha$-cadinol [17] [18]. So that, the present study is interested in production of silver, zinc and gold NPs by green synthesis method using $R$. epapposum flower extract.

The study was designed to investigate the ability of the methanolic extract of R. epapposum flowers to biosynthesized AgNPs, ZnNPs and AuNPs without using any harmful reducing or capping agents. Then, the features of the formed 
NPs were characterized by UV-Vis spectroscopy, XRD analysis, FTIR analysis and TEM. Further, the antifungal activity of the formed NPs was tested against $C$. albicans, $P$. exigua and $A$. melleus. In addition, their cytotoxicity on three cancer cell lines: Breast adenocarcinoma (MCF-7), Hepatocellular carcinoma (HepG-2) and colorectal carcinoma (HCT 116) human cell lines was also investigated.

\section{Materials and Methods}

\section{Collection of $R$. epapposum flowers and preparation of their methanolic}

\section{extract:}

Flowers of $R$. epapposum were collected from Al-Wadeen, Ahad Rafidah governorate, Assir region, Saudi Arabia at October 2019. Then, the collected flowers were cleaned, washed by dist. $\mathrm{H}_{2} \mathrm{O}$ and dried in the oven at $50^{\circ} \mathrm{C}$ for $24 \mathrm{~h}$ inside paper envelops. After drying, the flowers were powdered using an electric mill.

About $50 \mathrm{~g}$ flower powder was extracted in $250 \mathrm{ml} 70 \%$ methanol for $1 \mathrm{~h}$ in water bath at $40^{\circ} \mathrm{C}$. Then the mixture left for $48 \mathrm{~h}$ in the dark for complete extraction. The extraction mixture was filtered using Whatman filter paper number 1 , then the aliquot was dried by a rotary evaporator at $50^{\circ} \mathrm{C}$ to gain a semisolid material which completely dried to solid powder in the oven for $24 \mathrm{~h}$ at $40^{\circ} \mathrm{C}$.

\section{Biosynthesis of AgNPs, ZnNPs and AuNPs:}

Silver nitrate $\left(\mathrm{AgNO}_{3}\right)$ and Gold (III) chloride trihydrate $\left(\mathrm{HAuCl}_{4} \cdot 3 \mathrm{H}_{2} \mathrm{O}\right)$ purchased from (Sigma Aldrich, UK), while, Zinc Acetate; $\mathrm{Zn}\left(\mathrm{CH}_{3} \mathrm{CO}_{2}\right)_{2}$ and Methanol were purchased from (AnalaR grade: BDH Chemicals, England).

The tested NPs; AgNPs, ZnNPs and AuNPs were biosynthesized using the previously prepared flower extraction according to the method of [3] [19]. Firstly, an aqueous flower extract was prepared by dissolving $2 \mathrm{~g}$ from previously prepared flower solid powder in $200 \mathrm{ml}$ dist. $\mathrm{H}_{2} \mathrm{O}$ using magnetic stirrer. Then, the solutions of starting materials with conc. 1 molar were prepared in $100 \mathrm{ml}$ dist. $\mathrm{H}_{2} \mathrm{O}$ separately using the following weights $(\mathrm{g}) \mathrm{AgNO}_{3} ; 1.7, \mathrm{Zn}\left(\mathrm{CH}_{3} \mathrm{CO}_{2}\right)_{2}$; 2 and $\mathrm{HAuCl}_{4} \cdot 3 \mathrm{H}_{2} \mathrm{O} ; 3.3$. After that, $25 \mathrm{~mL}$ of aqueous flower extract was added dropwise with continuous magnetic stirring at room temperature until appearing of diagnostic colors for each metal NPs. Brown red color in the case of AgNPs, while in the cases of ZnNPs and AuNPs the detected colors were yellowish milky and dark pink respectively. This color change of the solutions is indicator for conversion of the metal particles from the large scale into nano scale. After that, each metallic NPs were settled by centrifugation at 10,500 rpm for 15 min. The NPs were subjected to the washing process with distilled water three times before drying them at $90^{\circ} \mathrm{C}$ for $24 \mathrm{~h}$ for obtaining powdered NPs.

\section{Characterization of AgNPs, ZnNPs and AuNPs:}

The absorbance of the resulted NPs was measured at UV range of $300-800$ $\mathrm{nm}$ by UV-Visible spectrophotometer (Cary $8454 \mathrm{UV}$-Vis Diode Array System, United State). Also, the XRD of the biosynthesized NPs were analyzed on glass 
substrate by using X-ray diffractometer Shimadzu X-ray ( $\mathrm{Cu} k a)$ Diffract meter XRD-6000 ( $\lambda=1.5406 \AA)$ operated at $30 \mathrm{kV}$ and 25 with a step of $0.02^{\circ}$ in the Bragg angles $2 \theta$ at a scanning rate of $20 \mathrm{~min}^{-1}$ at $30^{\circ}$ to $80^{\circ}$. The functional groups of the samples were investigated in the $400-4000 \mathrm{~cm}^{-1}$ range with a Thermo Nicolet 6700 Fourier transform infrared (FTIR) spectrometer (Thermo Scientific, Waltham, MA, USA). While the particle size and morphology of the tested NPs were observed by using Transmission Electron Microscopy JEOL TEM (Model 100 CXII) electron microscope.

\section{Antifungal activity of NPs using agar diffusion assay:}

Antifungal activity of the formed AgNPs, ZnNPs and AuNPs was screened against three pathogenic fungi; $C$. albicans, $P$. exigua and $A$. melleus. The tested pathogens were kindly provided by the Microbiology Research Laboratory, Biology Department, King Khalid University.

The yeast strain; C. albicans was activated in yeast agar (YA) medium at $27^{\circ} \mathrm{C}$

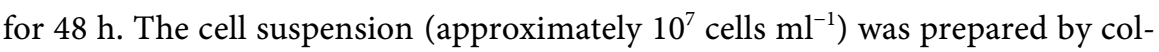
lecting the cells from new cultures by swabs and suspended them in $50 \mathrm{ml}$ distilled water in falcon tube and shaking well. The fungal strains; $P$. exigua and $A$. melleus were sub-cultured using PDA plates and incubated at $27{ }^{\circ} \mathrm{C}$ for 5 days. Fresh hyphae or spore suspensions of both $P$. exigua and A. melleus about $10^{7}$ hyphae or spore $\mathrm{ml}^{-1}$ were used.

The antifungal properties of the tested NPs were screened using the agar well diffusion method [4] [20]. For that purpose, $100 \mu \mathrm{L}$ from each of the previously prepared yeast and fungal suspensions were mixed separately with YA and PDA media before solidification and mix well then poured in Petri plates and let to solidify. Regular wells of $4 \mathrm{~mm}$ were made with a sterile cork borer in each plate. Serial dilutions (30, 60, 90 and $120 \mu \mathrm{g} / \mathrm{ml})$ from AgNPs, ZnNPs and AuNPs were prepared; then the wells filled by $50 \mu \mathrm{L}$ from each dilution. The plates were incubated at $27^{\circ} \mathrm{C}$, then the inhibition in the fungal growth was recorded by measuring the appeared inhibition zones after 24 hours for yeast and after 72 hours for fungal species. The obtained results were compared with, $60 \mu \mathrm{g} / \mathrm{ml}$ of nystatin as a positive control and $60 \mu \mathrm{L}$ dist. $\mathrm{H}_{2} \mathrm{O}$ as negative control. To investigate the antifungal activity of the crude extract of $R$. epapposum flowers; $60 \mu \mathrm{g} / \mathrm{ml}$ was tested against the tested fungi according to the used method. Each samples and controls treatments were repeated five times.

\section{Detection of cytotoxicity of the tested NPs:}

Breast adenocarcinoma (MCF-7) Hepatocellular carcinoma (HepG-2) and colorectal carcinoma (HCT 116) human cell lines were obtained from the American type culture collection (ATCC). Cells were maintained in RPMI-1640 supplemented with $(100 \mu \mathrm{g} / \mathrm{mL})$; penicillin $(100 \mathrm{units} / \mathrm{mL})$ and heat-inactivated fetal bovine serum $(10 \% \mathrm{v} / \mathrm{v})$ in a humidified, $5 \%(\mathrm{v} / \mathrm{v}) \mathrm{CO}_{2}$ atmosphere at $37^{\circ} \mathrm{C}$.

Sulforhodamine B Assay (SRB):

The cytotoxicity of the NPs was evaluated against (MCF-7, HepG2 \& HCT 116) human tumor cells using SRB. $90 \%$ confluency growing cells were trypsi- 
nized and cultured in a 96 well tissue culture plate ( 3000 cells/well) for $24 \mathrm{~h}$ before treatment with the tested NPs. Cells exposed to six different concentrations of each NPs $(0.01,0.1,1,10$, and $1000 \mu \mathrm{g})$ while the untreated cells served as control. The cells were incubated with the concentrations for $72 \mathrm{~h}$ and subsequently fixed with TCA $(10 \% \mathrm{w} / \mathrm{v})$ for $1 \mathrm{~h}$ at $4{ }^{\circ} \mathrm{C}$. After several washings, cells were stained by $0.4 \% \mathrm{w} / \mathrm{v}$ SRB solution for $10 \mathrm{~min}$ in dark place. Excess stain was washed with $1 \% \mathrm{v} / \mathrm{v}$ glacial acetic acid. After drying overnight, the SRB-stained cells were dissolved with Tris- $\mathrm{HCl}$ and the color intensity was measured in microplate reader at $540 \mathrm{~nm}$. The relation between viability percentage of each tumor cell line and NPs concentrations was analyzed to get the $\mathrm{IC}_{50}$ (dose of the drug which reduces survival to 50\%) using Sigma Plot 12.0 software. All the steps were repeated using the antitumor drug; Doxorubicin as control.

\section{Statistical analysis:}

Statistical analysis of the present study was conducted, using the mean, standard deviation (SD) and analysis of variance (ANOVA) using Microsoft Excel 2016 program and the online free source; Free Statistics Calculators version 4.0. Statistical significance was acceptable to a level of $p<0.05$. Graphs were plotted using GraphPad Prism software, version 6.00 (GraphPad Software, La Jolla, CA).

\section{Results and Discussion}

\section{Biosynthesis of AgNPs, ZnNPs and AuNPs:}

The biosynthesis reaction started within a few minutes and the color reaction was observed in which clear $\mathrm{AgNO}_{3}, \mathrm{Zn}\left(\mathrm{CH}_{3} \mathrm{CO}_{2}\right)_{2}$ and $\mathrm{HAuCl}_{4} \cdot 3 \mathrm{H}_{2} \mathrm{O}$ solutions were changed into brown red color, yellowish milky color and dark pink respectively. The new colors indicated the formation of the corresponding NPs and confirm the ability of the methanolic extract of $R$. epapposum flowers to synthesize the NPs (Photo 1).

\section{Characterization of AgNPs, ZnNPs and AuNPs}

The UV-Vis spectra of the formed AgNPs, ZnNPs and AuNPs are shown in Figure 1. The distinct peaks observed at 423,375 and $525 \mathrm{~nm}$ are distinguished to surface plasmon resonance of AgNPs, ZnNPs and AuNPs respectively. These results are compatible to results of other researches [1] [9]. The obtained nanoparticles showed high stability at the recorded peaks.

Figure 2 represented the XRD pattern of the tested NPs. In each pattern, four distinct diffraction peaks are observed. In the case of AgNPs the peaks are observed at $2 \theta$ equal $38.16^{\circ}, 44.42^{\circ}, 64.41^{\circ}$, and $77.49^{\circ}$. While, the detected peaks of AuNP were at $2 \theta$ equal $38.08^{\circ}, 44.2^{\circ}, 64.49^{\circ}$, and $77.60^{\circ}$. These four peaks are indicating that the AgNPs and AuNPs phase exist in the form of face centered spherical structure. Peaks of ZnNPs were observed at $2 \theta$ equal $31.95^{\circ}, 34.23^{\circ}$, $36.29^{\circ}, 47.56^{\circ}, 56.67^{\circ}, 62.91^{\circ}, 66.28^{\circ}, 67.95^{\circ}, 69.03^{\circ}, 72.59^{\circ}$, and $77.09^{\circ}$ corresponding to the $100,002,101,102,110,103,200,112$ and 201 planes. Thus, the $\mathrm{X}$-ray diffraction study clearly demonstrates the crystalline nature of the biosynthesized AgNPs, ZnNPs and AuNPs. These results are agreed some earlier researches [1] [4] [21]. 


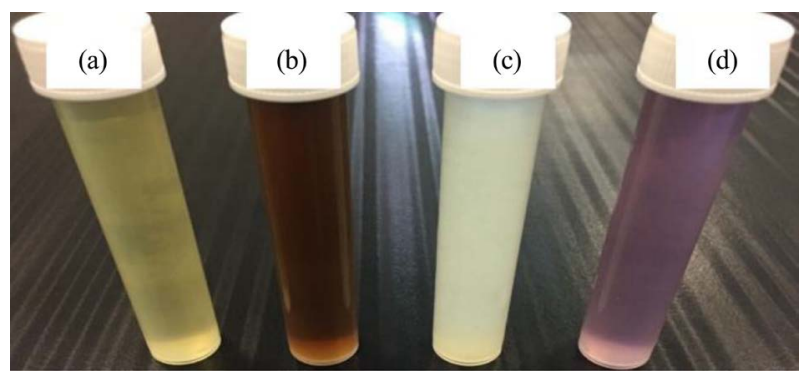

Photo 1. Biosynthesis of AgNPs, ZnNPs and AuNPs using R. epapposum flower extract (a). Reaction with $1 \mathrm{mM}$ of: $\mathrm{AgNO}_{3}$ (b), $\mathrm{Zn}\left(\mathrm{CH}_{3} \mathrm{CO}_{2}\right)_{2}$ (c) and $\mathrm{HAuCl}_{4} \cdot 3 \mathrm{H}_{2} \mathrm{O}$ (d).

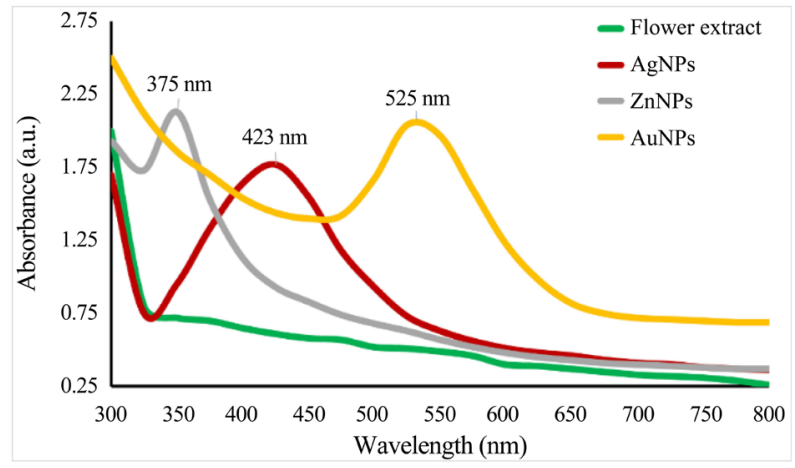

Figure 1. UV-Vis spectrum analysis of the formed AgNPs, ZnNPs and AuNPs.
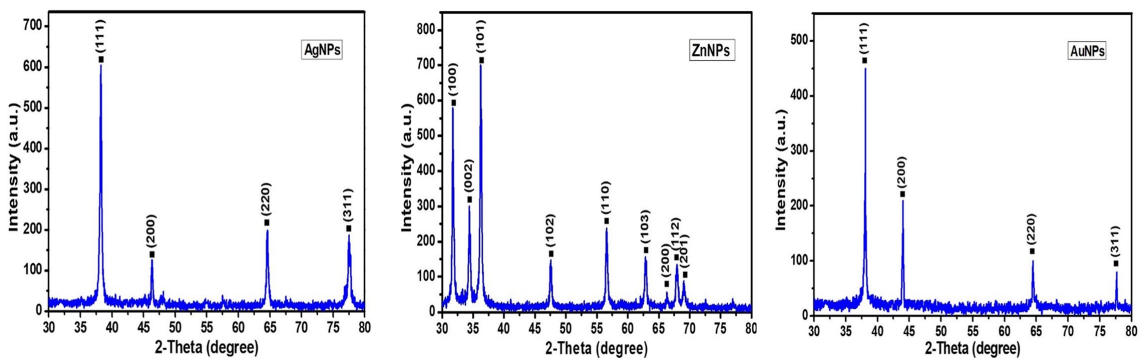

Figure 2. XRD of the green synthesized AgNPs, ZnNPs and AuNPs.

To study the morphology of the biosynthesized AgNPs, ZnNPs and AuNPs, the TEM analysis was carried out. The micrographs revealed that AgNPs were homogeneous and spherical in shape, with a size range from $3-17 \mathrm{~nm}$ with average diameter $16.3 \pm 3 \mathrm{~nm}$. Shape of ZnNPs was approximately triangle and hexagonal, in which their size ranged from $9-30.3 \mathrm{~nm}$ and the average diameter was $23.5 \pm 10 \mathrm{~nm}$ (Photo 2). Most of the AuNPs were spherical in shape and their size ranged from $3-19 \mathrm{~nm}$ with average diameter $17.9 \pm 3 \mathrm{~nm}$.

The FT-IR spectra of AgNPs, ZnNPs and AuNPs are shown in Figure 3. The absorption bands at 3405 to $3438 \mathrm{~cm}^{-1}, 2919$ to $2935 \mathrm{~cm}^{-1}$ and 2850 to $2877 \mathrm{~cm}^{-1}$ are assigned to $\mathrm{O}-\mathrm{H}$ stretching mode of alcohols/phenols and $\mathrm{N}-\mathrm{H}$ vibration of amines. The medium band at 1622 to $1630 \mathrm{~cm}^{-1}$ is corresponded to conjugation effects of $\mathrm{C}=\mathrm{O}$ stretching of carbonyl groups. The strong band 1064 to $1081 \mathrm{~cm}^{-1}$ is corresponded to aliphatic amines. While the bands at 925 to $553 \mathrm{~cm}^{-1}$ were corresponded to stretching of haloalkanes [10]. 

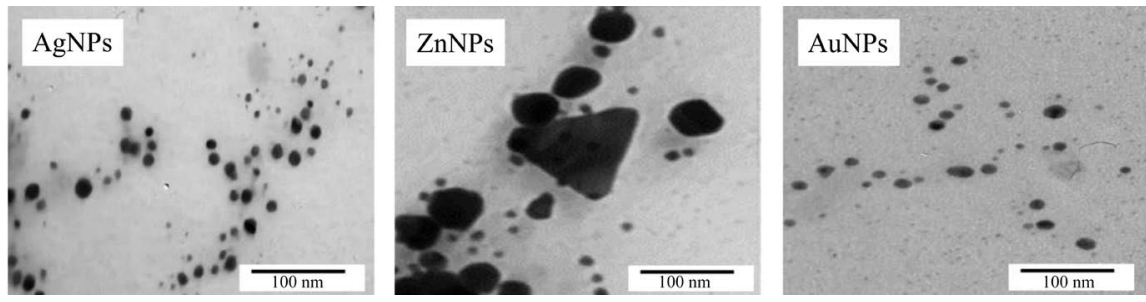

Photo 2. TEM images of the green synthesized AgNPs, ZnNPs and AuNPs.

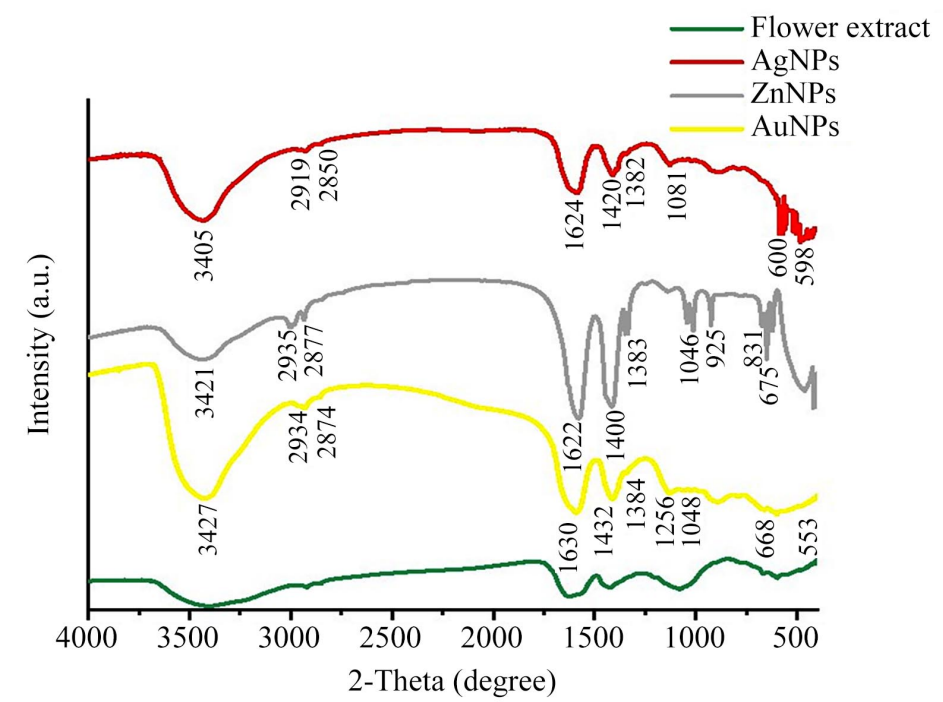

Figure 3. FT-IR spectra of the green synthesized AgNPs, ZnNPs and AuNPs.

\section{Antifungal activity of AgNPs, ZnNPs and AuNPs:}

The antifungal activity of the biosynthesized AgNPs, ZnNPs and AuNPs have been investigated against $C$. albicans, $P$. exigua and $A$. melleus using the agar well diffusion method. It was noticed that the biosynthesized AgNPs, ZnNPs and AuNPs and the antibiotic (positive control) exhibited an antifungal activity against the tested pathogenic fungi. While the flower plant extract has a negligible effect against the pathogenic yeast and fungal species (Table 1 and Photo 3 ). All the biosynthesized AgNPs, ZnNPs and AuNPs showed a significant antifungal activity against the tested fungi where the effect increased proportionally with increasing the concentration. AuNPs showed least activity for all the organisms.

\section{Cytotoxicity of AgNPs, ZnNPs and AuNPs:}

The cytotoxic activity of the formed AgNPs, ZnNPs and AuNPs mediated by the methanolic extract of $R$. epapposum was evaluated against MCF-7, HepG-2 and HCT 116 human cancer cell lines using SRB assay. The best cytotoxic effect was recorded by AgNPs where the $\mathrm{IC}_{50}$ values were $0.55 \pm 0.01,0.98 \pm 0.08$ and $1.66 \pm 0.18(\mu \mathrm{g} / \mathrm{mL})$ against MCF-7, HepG2 and HCT 116 respectively. While, the lowest cytotoxic effect against these cancer cell lines was exhibited by AuNPs. On the other hand, mild cytotoxic activity was investigated by the crude extract of $R$. epapposum flowers and ZnNPs (Table 2 and Figure 4). 
Table 1. Antifungal activities of the formed NPs against the used pathogenic fungi.

\begin{tabular}{|c|c|c|c|c|c|c|}
\hline & \multicolumn{6}{|c|}{ Inhibition zones (mean $\pm \mathrm{SD}$ ) $\mathrm{mm}$} \\
\hline & $30 \mu \mathrm{g} / \mathrm{ml}$ & $60 \mu \mathrm{g} / \mathrm{ml}$ & $90 \mu \mathrm{g} / \mathrm{ml}$ & $120 \mu \mathrm{g} / \mathrm{ml}$ & Extract $^{\mathrm{a}}$ & Nystatin $^{\mathrm{a}}$ \\
\hline \multicolumn{7}{|c|}{ Candida albicans } \\
\hline AgNPs & $15.3 \pm 0.53$ & $17.0 \pm 0.50$ & $20.0 \pm 1.2$ & $23.5 \pm 0.67$ & & \\
\hline ZnNPs & $15.5 \pm 0.42$ & $17.5 \pm 0.82$ & $19.5 \pm 0.5$ & $21.2 \pm 0.46$ & $3.2 \pm 0.5$ & $15.6 \pm 0.62$ \\
\hline AuNPs & $13.2 \pm 0.38$ & $15.2 \pm 0.34$ & $18.2 \pm 0.9$ & $19.8 \pm 0.82$ & & \\
\hline \multicolumn{7}{|l|}{ ANOVA } \\
\hline F-value: & 40.469 & 21.146 & 5.180 & 39.275 & & \\
\hline P-value: & $0.000^{* *}$ & $0.000^{* *}$ & $0.024^{*}$ & $0.000^{* *}$ & & \\
\hline \multicolumn{7}{|c|}{ Phoma exigua } \\
\hline AgNPs & $14.0 \pm 0.52$ & $15.2 \pm 0.4$ & $17.0 \pm 0.58$ & $19.3 \pm 0.32$ & & \\
\hline ZnNPs & $16.0 \pm 0.23$ & $18.5 \pm 0.54$ & $20 \pm 0.49$ & $22.0 \pm 0.48$ & $12.2 \pm 0.92$ & $19.5 \pm 0.2$ \\
\hline AuNPs & $11.0 \pm 1.20$ & $13.2 \pm 0.72$ & $15.4 \pm 0.6$ & $18.2 \pm 0.25$ & & \\
\hline \multicolumn{7}{|l|}{ ANOVA } \\
\hline F-value: & 53.87 & 110.77 & 87.347 & 145.080 & & \\
\hline P-value: & $0.000^{* *}$ & $0.000^{* *}$ & $0.000^{* *}$ & $0.000^{* *}$ & & \\
\hline \multicolumn{7}{|c|}{ Aspergillus melleus } \\
\hline AgNPs & $12.5 \pm 0.25$ & $14.5 \pm 0.24$ & $17.5 \pm 0.6$ & $19.7 \pm 0.33$ & & \\
\hline ZnNPs & $13.6 \pm 0.59$ & $13.2 \pm 0.39$ & $15.0 \pm 0.84$ & $17.5 \pm 0.76$ & $0.00 \pm 0.00$ & $16.7 \pm 0.3$ \\
\hline AuNPs & $6.3 \pm 0.92$ & $8.4 \pm 0.54$ & $10.0 \pm 0.24$ & $14.3 \pm 0.26$ & & \\
\hline \multicolumn{7}{|l|}{ ANOVA } \\
\hline F-value: & 184.84 & 829.54 & 194.75 & 146.66 & & \\
\hline P-value: & $0.000^{\star *}$ & $0.000^{* *}$ & $0.000^{\star *}$ & $0.000^{\star *}$ & & \\
\hline
\end{tabular}

${ }^{a}$ Concentration used is $60 \mu \mathrm{g} / \mathrm{ml}$. SD: Standard Deviation. *: Significant at $\mathrm{P}<0.05$; ${ }^{* *}$ : Highly significant at $\mathrm{P}<0.05$.

Table 2. Cytotoxicity of the methanolic extract of $R$. epapposum and Ag NPs, Zn NPs and $\mathrm{Au}$ NPs against three cancer cell lines.

\begin{tabular}{cccc}
\hline & \multicolumn{3}{c}{$\mathrm{IC}_{50}(\mu \mathrm{g} / \mathrm{mL}) \pm \mathrm{SD}$} \\
\cline { 2 - 4 } & MCF-7 & HepG2 & HCT 116 \\
\hline Organic extract & $24.24 \pm 1.46$ & $29.61 \pm 2.09$ & $24.11 \pm 1.56$ \\
AgNPs & $0.55 \pm 0.01$ & $0.98 \pm 0.08$ & $1.66 \pm 0.18$ \\
ZnNPs & $12.23 \pm 0.92$ & $0.70 \pm 0.01$ & $26.28 \pm 2.86$ \\
AuNPs & $55.02 \pm 1.31$ & $66.44 \pm 1.40$ & $169.87 \pm 1.53$ \\
ANOVA & & & \\
F-value: & 2338.79 & $\mathbf{3 0 5 6 . 9 5}$ & $\mathbf{9 1 4 7 . 1 3}$ \\
P-value: & $\mathbf{0 . 0 0 0 ^ { * * }}$ & $\mathbf{0 . 0 0 0 * *}$ & $\mathbf{0 . 0 0 0 ^ { * * }}$ \\
\hline
\end{tabular}

SD: Standard Deviation. ${ }^{* *}$ : Highly significant at $\mathrm{P}<0.05$. 
(a)

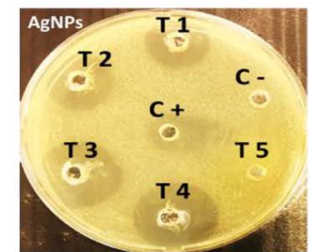

(b)

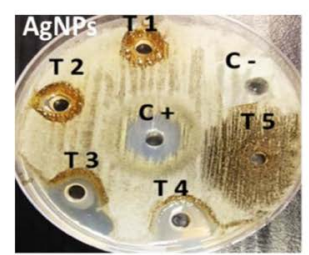

(c)

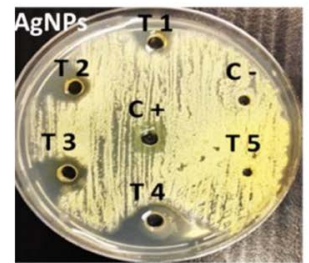

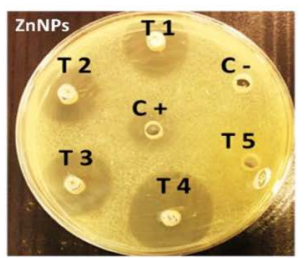
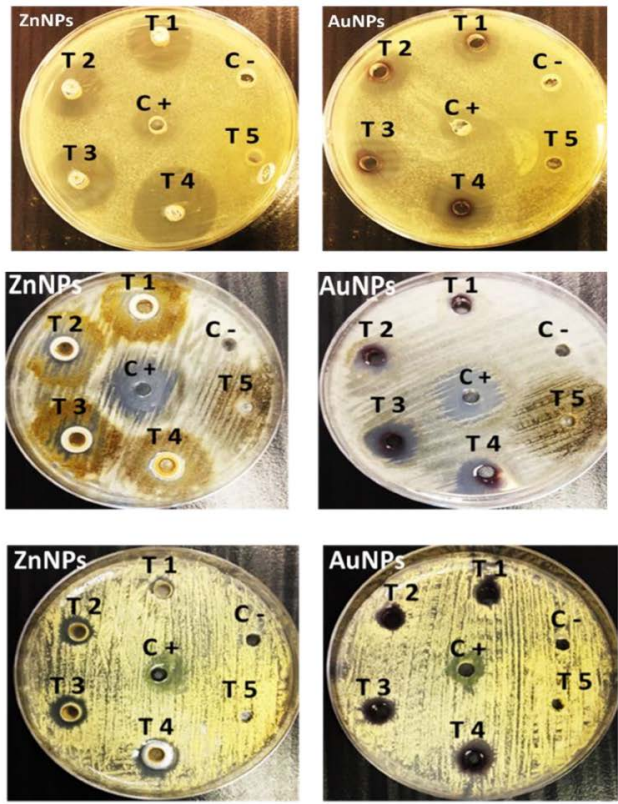

Photo 3. The antifungal activity of the biosynthesized NPs against $\boldsymbol{C}$. albicans (a), $\boldsymbol{P}$. exigua (b) and $\boldsymbol{A}$. melleus (c) at different concentrations; T1: $30 \mu \mathrm{g} / \mathrm{ml}$, T2: $60 \mu \mathrm{g} / \mathrm{ml}$, T3: $90 \mu \mathrm{g} / \mathrm{ml}$, T4: $120 \mu \mathrm{g} / \mathrm{ml}$, T5: $60 \mu \mathrm{g} / \mathrm{ml} R$. epapposum flower extract, C -: -ve control and C+: +ve control (nystatin).
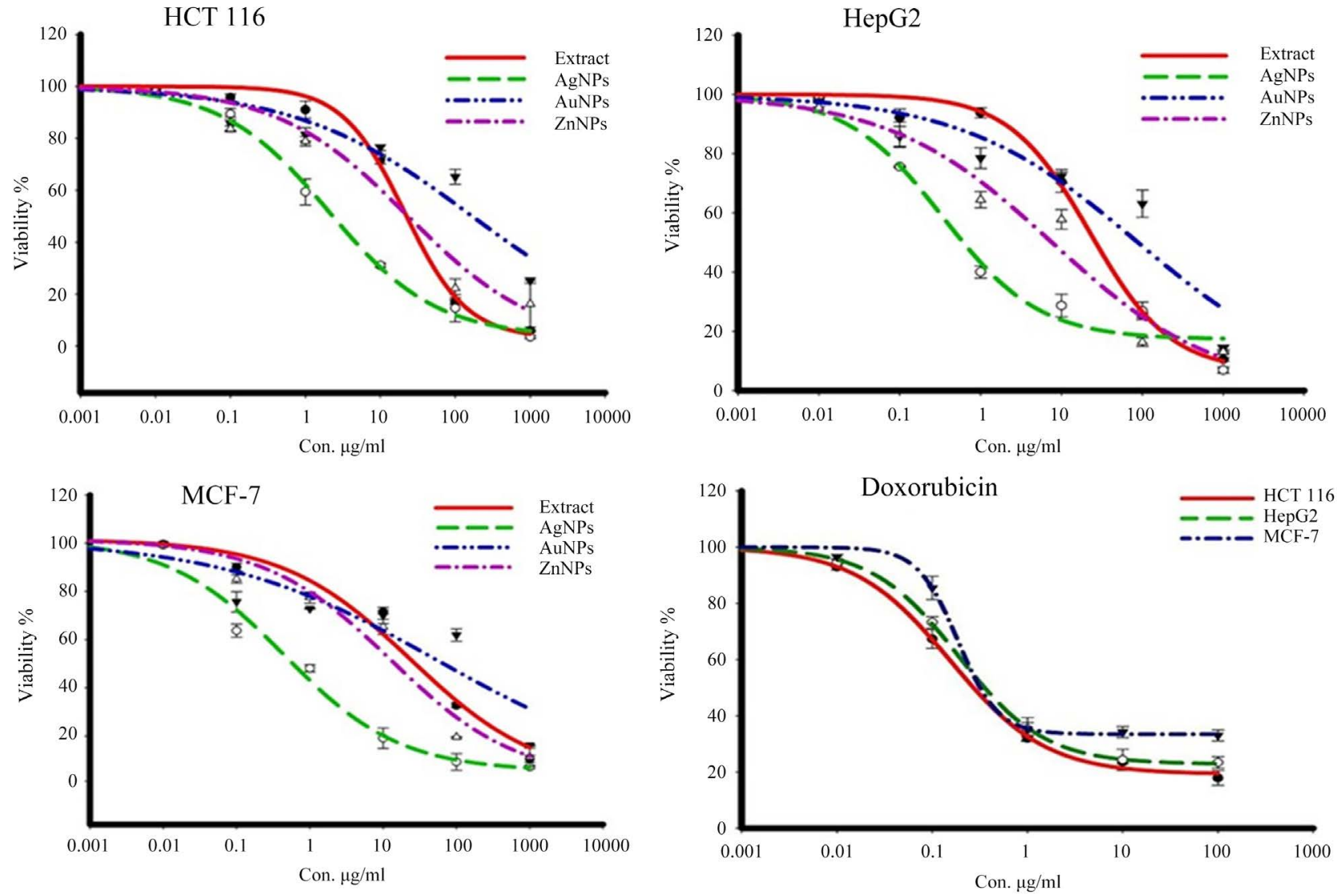

Figure 4. Cytotoxicity of the AgNPs, ZnNPs and AuNPs against MCF-7, HepG-2 and HCT 116 human cell lines. Doxorubicin served as control. 


\section{Conclusion}

The silver, zinc and gold NPs were successfully prepared biologically using the alcoholic extract of $R$. epapposum flowers and the starting materials: $\mathrm{AgNO}_{3}, \mathrm{Zn}$ $\left(\mathrm{CH}_{3} \mathrm{CO}_{2}\right)_{2}$ and $\mathrm{HAuCl}_{4} \cdot 3 \mathrm{H}_{2} \mathrm{O}$. Then, the morphology and particle size of the formed NPs were established by UV spectroscopy, XRD, TEM and FT-IR. The tested NPs represented an antifungal activity with different degrees against $C$. albicans, $P$. exigua and $A$. melleus. Moreover, the formed NPs showed cytotoxic effects against three cancer cell lines (MCF-7, HepG-2 and HCT 116) where AgNPs exhibited the best results. According to these results, it was concluded that, the tested AgNPs, ZnNPs and AuNPs might be used as antitumor materials, but this still needs further studies.

\section{Acknowledgements}

The authors would like to present their acknowledgements to everyone helped in success of this work.

\section{Conflicts of Interest}

The authors declare no conflicts of interest regarding the publication of this paper.

\section{References}

[1] Sukri, S.N.A.M., Shameli, K., Wong, M.M.-T., Teow, S.-Y., Chew, J. and Ismail, N.A. (2019) Cytotoxicity and Antibacterial Activities of Plant-Mediated Synthesized Zinc Oxide (ZnO) Nanoparticles Using Punica granatum (Pomegranate) Fruit Peels Extract. Journal of Molecular Structure, 1189, 57-65. https://doi.org/10.1016/j.molstruc.2019.04.026

[2] Sun, Q., Qiu, S.T., Gu, H.Y., Yao, M., et al. (2019) Biosynthesis, Characterization and Biological Activities of Silver Nanoparticles from Pogostemon cablin Benth. Methanolic leaf extract. Journal of Nanoscience and Nanotechnology, 19, 4109-4115. https://doi.org/10.1166/jnn.2019.16282

[3] Valsalam, S., Agastian, P., Esmail, G.A., Ghilan, A.-K.M., Al-Dhabi, N.A. and Arasu, M.V. (2019) Biosynthesis of Silver and Gold Nanoparticles Using Musa acuminata colla Flower and Its Pharmaceutical Activity against Bacteria and Anticancer Efficacy. Journal of Photochemistry and Photobiology B: Biology, 201, Article ID: 111670. https://doi.org/10.1016/j.jphotobiol.2019.111670

[4] Ghramh, H.A., Khan, K.A., Ibrahim, E.H. and Setzer, W.N. (2019) Synthesis of Gold Nanoparticles (AuNPs) Using Ricinus communis Leaf Ethanol Extract, Their Characterization, and Biological Applications. Nanomaterials, 9, 765. https://doi.org/10.3390/nano9050765

[5] Velsankar, K., Sudhahar, S., Parvathy, G. and Kaliammal, R. (2020) Effect of Cytotoxicity and Antibacterial Activity of Biosynthesis of $\mathrm{ZnO}$ Hexagonal Shaped $\mathrm{Na}$ noparticles by Echinochloa frumentacea Grains Extract as a Reducing Agent. Materials Chemistry and Physics, 239, Article ID: 121976. https://doi.org/10.1016/j.matchemphys.2019.121976

[6] Nasrollahzadeh, M., Sajadi, S.M., Babaei, F. and Maham, M. (2015) Euphorbia helioscopia Linn as a Green Source for Synthesis of Silver Nanoparticles and Their 
Optical and Catalytic Properties. Journal of Colloid and Interface Science, 450, 374-380. https://doi.org/10.1016/j.jcis.2015.03.033

[7] Rupa, E.J., Anandapadmanaban, G., Mathiyalagan, R. and Yang, D.-C. (2018) Synthesis of Zinc Oxide Nanoparticles from Immature Fruits of Rubus coreanus and Its Catalytic Activity for Degradation of Industrial Dye. Optik, 172, 1179-1186.

https://doi.org/10.1016/j.ijleo.2018.07.115

[8] Sorbiun, M., Mehr, E.S., Ramazani, A. and Fardood, S.T. (2018) Green Synthesis of Zinc Oxide and Copper Oxide Nanoparticles Using Aqueous Extract of Oak Fruit Hull (Jaft) and Comparing Their Photocatalytic Degradation of Basic Violet 3. International Journal of Environmental Research, 12, 29-37.

https://doi.org/10.1007/s41742-018-0064-4

[9] Hao, D., Xu, Y., Zhao, M., Ma, J., Wei, Y. and Wang, X. (2020) RETRACTED: Biosynthesis of Clinacanthus nutans Lindau Leaf Extract Mediated Ag NPs, Au NPs and Their Comparative Strong Muscle Relaxant, Analgesic Activities for Pain Management in Nursing Care for Using in Intensive Nursing Care Unit. Journal of Photochemistry and Photobiology B: Biology, 202, Article ID: 111674. https://doi.org/10.1016/j.jphotobiol.2019.111674

[10] Anjana, P., Bindhu, M., Umadevi, M. and Rakhi, R. (2019) Antibacterial and Electrochemical Activities of Silver, Gold, and Palladium Nanoparticles Dispersed Amorphous Carbon Composites. Applied Surface Science, 479, 96-104. https://doi.org/10.1016/j.apsusc.2019.02.057

[11] Parveen, K., Banse, V. and Ledwani, L. (2016) Green Synthesis of Nanoparticles: Their Advantages and Disadvantages. AIP Conference Proceedings, 1724, Article ID: 020048. https://doi.org/10.1063/1.4945168

[12] Zikalala, N., Matshetshe, K., Parani, S. and Oluwafemi, O.S. (2018) Biosynthesis Protocols for Colloidal Metal Oxide Nanoparticles. Nano-Structures \& Nano-Objects, 16, 288-299. https://doi.org/10.1016/j.nanoso.2018.07.010

[13] Velusamy, P., Kumar, G.V., Jeyanthi, V., Das, J. and Pachaiappan, R. (2016) Bio-Inspired Green Nanoparticles: Synthesis, Mechanism, and Antibacterial Application. Toxicological Research, 32, 95-102.

https://doi.org/10.5487/TR.2016.32.2.095

[14] Dobrucka, R. (2018) Antioxidant and Catalytic Activity of Biosynthesized CuO Nanoparticles Using Extract of Galeopsidis herba. Journal of Inorganic and Organometallic Polymers and Materials, 28, 812-819. https://doi.org/10.1007/s10904-017-0750-2

[15] Fatemeh, J., Zahra, L. and Hossein, A. (2018) Medicinal Plants: Past History and Future Perspective. Journal of Herbmed Pharmacology, 7, 1-7.

https://doi.org/10.15171/jhp.2018.01

[16] Medda, S., Hajra, A., Dey, U., Bose, P. and Mondal, N.K. (2015) Biosynthesis of Silver Nanoparticles from Aloe vera Leaf Extract and Antifungal Activity against Rhizopus sp. and Aspergillus sp. Applied Nanoscience, 5, 875-880. https://doi.org/10.1007/s13204-014-0387-1

[17] Akbar, S. and Al-Yahya, M. (2011) Screening of Saudi Plants for Phytoconstituents, Pharmacological and Antimicrobial Properties. Australian Journal of Medical Herbalism, 23, 76-87.

[18] Awad, M. and Abdelwahab, A. (2016) Chemical Diversity of Essential Oils from Flowers, Leaves, and Stems of Rhanterium epapposum Oliv. Growing in Northern Border Region of Saudi Arabia. Asian Pacific Journal of Tropical Biomedicine, 6, 767-770. https://doi.org/10.1016/j.apjtb.2016.07.010 
[19] Kumar, H.N., Mohana, N.C., Nuthan, B., Ramesha, K., Rakshith, D., Geetha, N., et al. (2019) Phyto-Mediated Synthesis of Zinc Oxide Nanoparticles Using Aqueous Plant Extract of Ocimum americanum and Evaluation of Its Bioactivity. SN Applied Sciences, 1, Article No. 651. https://doi.org/10.1007/s42452-019-0671-5

[20] Bocate, K.P., Reis, G.F., de Souza, P.C., Oliveira Junior, A.G., Durán, N., Nakazato, G., et al. (2019) Antifungal Activity of Silver Nanoparticles and Simvastatin against Toxigenic Species of Aspergillus. International Journal of Food Microbiology, 291, 79-86. https://doi.org/10.1016/j.ijfoodmicro.2018.11.012

[21] Hemmati, S., Rashtiani, A., Zangeneh, M.M., Mohammadi, P., Zangeneh, A. and Veisi, H. (2019) Green Synthesis and Characterization of Silver Nanoparticles Using Fritillaria Flower Extract and Their Antibacterial Activity against Some Human Pathogens. Polyhedron, 158, 8-14. https://doi.org/10.1016/j.poly.2018.10.049 